Série des Documents de Travail

$n^{\circ}$ 2020-15

\title{
Why are Low-Skilled Workers less Mobile? The role of Mobility Costs and Spatial Frictions
}

\author{
Benoît SCHMUTZ' \\ Modibo SIDIBÉ ${ }^{2}$ \\ Élie VIDAL-NAQUET ${ }^{3}$
}

Les documents de travail ne reflètent pas la position du CREST et n'engagent que leurs auteurs.

Working papers do not reflect the position of CREST but only the views of the authors.

\footnotetext{
${ }^{1}$ Ecole Polytechnique and CREST; benoit.schmutz@polytechnique.edu

${ }^{2}$ Duke University; modibo.sidibe@duke.edu

${ }^{3}$ Aix-Marseille School of Economics; elie.vidal-naquet@univ-amu.fr
} 


\title{
Why are Low-Skilled Workers less Mobile? The Role of Mobility Costs and Spatial Frictions*
}

\author{
Benoît Schmutz $^{\dagger} \quad$ Modibo Sidibé ${ }^{\ddagger} \quad$ Élie Vidal-Naquet ${ }^{\S}$
}

June 15,2020

\begin{abstract}
Workers' propensity to migrate to another local labor market varies a lot by occupation. We use the model developed by Schmutz and Sidibé (2019) to quantify the impact of mobility costs and search frictions on this mobility gap. We estimate the model on a matched employer-employee panel dataset describing labor market transitions within and between the 30 largest French cities for two groups at both ends of the occupational spectrum and find that: (i) mobility costs are very comparable in the two groups, so they are three times higher for blue-collar workers relative to their respective expected income; (ii) Depending on employment status, spatial frictions are between 1.5 and 3.5 times higher for blue-collar workers; (iii) Moving subsidies have little (and possibly negative) impact on the mobility gap, contrary to policies targeting spatial frictions.
\end{abstract}

Keywords: mobility costs, spatial frictions, migration, local labor markets, occupation

JEL Classification: J61, J64, R12, R23

${ }^{*}$ We thank Franck Malherbet and seminar participants in Aix-Marseille School of Economics for comments. This study was made possible by a public grant overseen by the French National Research Agency (ANR) as part of the "Investissements d'Avenir" program (Idex Grant Agreement No. ANR-11-IDEX-ooo3- 02/Labex ECODEC No. ANR-11-LABEX-o047 and Equipex reference: ANR-10- EQPX-17-Centre d'accès sécurisé aux données CASD).

${ }^{\dagger}$ Ecole Polytechnique and CREST; benoit.schmutz@polytechnique.edu

${ }_{\ddagger}^{\ddagger}$ Duke University; modibo.sidibe@duke.edu

$\S$ Aix-Marseille School of Economics; elie.vidal-naquet@univ-amu.fr 


\section{Introduction}

While workers' ability to take advantage of remote opportunities is one of the drivers of a successful career, it has long been known to vary a lot with skill or occupational groups (Schwartz, 1973). As shown in Table 1 for the 2002-2006 period in France, manual (hereafter, blue-collar) workers have the same aggregate mobility rate as managers (hereafter, whitecollar), but they are much more likely to only move close-by and remain in the same local labor market.

Table 1: The regional mobility gap

\begin{tabular}{lccccc}
\hline & $\begin{array}{c}\text { Has changed } \\
\text { place of } \\
\text { residence }\end{array}$ & $\begin{array}{c}\text { within } \\
\text { city }\end{array}$ & $\begin{array}{c}\text { Has moved } \\
\text { département }\end{array}$ & $\begin{array}{c}\text { within } \\
\text { region }\end{array}$ & $\begin{array}{c}\text { between } \\
\text { regions }\end{array}$ \\
\hline Blue-collar & $32.7 \%$ & $12.6 \%$ & $13.4 \%$ & $3.0 \%$ & $3.7 \%$ \\
White-collar & $31.9 \%$ & $10.7 \%$ & $9.2 \%$ & $5.0 \%$ & $7.0 \%$ \\
\hline P-value difference & $60 \%$ & $6.5 \%$ & $<0.1 \%$ & $0.1 \%$ & $<0.1 \%$ \\
\hline
\end{tabular}

Notes: (i) Retrospective mobility over the 2002-2006 period based on current occupation; (ii) within city: live in a new dwelling in the same municipality; within département: live a new municipality, not in a new département; within region: live in a new département, not in a new region; between regions: live in a new region; (iii) there are 21 regions (using the definition prior to 2016), 94 départements and over 35 thousand municipalities in continental France; (iv) Blue-collar and white-collar correspond to the French aggregate occupational classification PCS6 and $\mathrm{PCS}_{3}$; (v) N=2,933 for white-collar and $\mathrm{N}=4,090$ for blue-collar; (vi) Statistics use survey weights and p-value difference is the p-value associated with the occupational dummy in a bivariate regression on the pooled sample using a probit model.

Source: National Housing Survey 2006

If migration is an investment, this regional mobility gap may be driven by differences in returns to migration, in the cost of migration, or both. In this paper, we use a dynamic model of job search in a system of local labor markets that explicitly controls for the returns to migration in order to quantify the main two barriers to mobility: migration costs, which encompass psychic and social costs, switching costs on the housing market and actual cost of moving; and spatial frictions, which lower workers' ability to hear about or apply to remote job opportunities.

Following Postel-Vinay and Robin (2002), we estimate the model separately on two panels of manual workers and managers under the approximation that these two polar occupations operate on two separate labor markets. The model and the identification strategy are borrowed from Schmutz and Sidibé (2019), who show how spatial frictions and mobility costs can be separately identified provided information on both labor flows and wage dynamics is available. The estimation is performed using the simulated method of moments based on local population size and wage distributions, as well as labor flows and wage dynamics associated with both within-city and between-city transitions.

Results consist of a set of city-specific parameters characterizing the level of frictions and the wage offer distributions at the city level, as well as the integration of each city to the aggregate labor market (spatial frictions and mobility costs), for both blue-collar and white-collar 
workers. Our main findings are fourfold: first, we estimate that blue-collar workers face the same mobility costs as white-collar workers, even though their average expected income is three times lower. Second, the magnitude of job arrival rates from other cities relative to local job arrival rates is higher for white-collar workers, especially when they are unemployed. Third, linear decompositions show that white-collar workers' ability to search for a job remotely is positively correlated with both their employment rate and their average earnings, whereas this is not the case of blue-collar workers. Fourth, counterfactual simulations show that relocation subsidies have little impact on the mobility gap, contrary to policies aimed at equalizing spatial frictions across occupations. Relocation subsidies may even prove detrimental to blue-collars' mobility in the long run, because they allow them to settle into less integrated cities, from which they will not be able to subsequently move away.

Relationship to the literature The approach to migration chosen by Schmutz and Sidibé (2019) is not very different from the study of inter-firm mobility. The model is a partial equilibrium random search model à-la-McCall (1970), where individuals do not only change firms but also move across space if the new firm is located in another local labor market. ${ }^{1}$ In addition, workers also look for jobs while employed. Labor mobility is subject to endogenous mechanisms that are difficult to identify without a structural approach. ${ }^{2}$ The main reference in the field is the study by Kennan and Walker (2011), who develop a rich dynamic migration model between the US states and obtain an estimate of mobility costs. However, they assume that workers do not face frictions when they search for a job, which makes it impossible to identify reallocation cost from impediments to the spatial integration of the labor market. Therefore, the low mobility rate that they observe in the data may only be rationalized with very high mobility cost estimates. Schmutz and Sidibé (2019) show that a random search framework enables to distinguish between these different mechanisms and that failing to account for spatial frictions in job search yields mobility cost estimates that are higher by one order of magnitude. ${ }^{3}$ This finding has potential policy implications, because relocation subsidies are unlikely to be effective if local labor markets are very segmented.

However, Schmutz and Sidibé (2019) consider ex-ante identical workers, despite a longstanding literature documenting the links between individual characteristics and localization strategies. The two main characteristics that have been put forward are qualifications and age. ${ }^{4}$ A prominent feature of internal migration in many countries is that the youngest and the most skilled are more prone to move to another region (Greenwood, 1997). Age is undoubtedly a very important determinant. ${ }^{5}$ However, the steady-state markovian model that

\footnotetext{
${ }^{1}$ Local labor markets are defined as spaceless objects where workers both live and work, so that the commuting dimension of job search is not considered, contrary to Manning and Petrongolo (2017).

${ }^{2}$ In a pioneer study on the US, Dahl (2002) modeled migration strategies as a static arbitrage problem, which is a strong assumption when one seeks to understand the complexity of individual careers (Gallin, 2004).

${ }^{3}$ The integration of spatial dimension into job-search and matching models is quite recent. However, the need to integrate space into these models was demonstrated in older studies (Burda and Profit, 1996).

${ }^{4} \mathrm{~A}$ third one is gender. However, literature on the structural modeling of the joint location problem is still burgeoning because data requirements are very high. Like Schmutz and Sidibé (2019), we focus on a sample of males.

If migration as an investment in human capital, which aims to increase productivity, younger workers will have greater returns (Sjaastad, 1962). In addition, young workers have less location specific human capital and
} 
we use is not well-suited to study the impact of age and we choose to focus on occupation (as a proxy for qualification) instead. Structural evidence on the impact of qualification on migration is more sparse, because structural papers tend to study homogeneous samples in order to minimize the number of dimensions of heterogeneity. ${ }^{6}$ A significant contribution to the understanding of why skilled and unskilled workers make different location choices is the study of Dahl (2002), who estimates a Roy model of mobility between the US states and shows that the most skilled workers will choose their location according to the returns to their skills. ${ }^{7}$ However, this study focuses on the return side. How migration costs vary with skill is largely unknown. ${ }^{8}$ High-skilled workers are more likely to be home-owners. On the other hand, low-skilled workers are more likely to rely on informal location-specific networks in their daily lives and they are more likely to live in public housing, which is allocated in a decentralized manner that does not favor regional moves. In this paper, we find surprisingly little difference between mobility cost estimates for blue-collar and white-collar workers.

For the reasons discussed above, there is even less evidence about differences in spatial search costs. In early quantitative work, Schwartz (1973) compared the effects of distance on different qualification groups and showed that the distance elasticity to the probability of migrating decreased with the level of education. He argued that this effect was reflecting the fact that high-skilled workers dispose of more sophisticated means of accessing information, which are not impacted by distance. This theory is difficult to test with administrative data. However, our framework allows us to distinguish between the job search process of unemployed and employed workers, who surely use different information channels. We show that high-skilled workers are better connected to other cities than low-skilled workers overall but that the gap is more pronounced for unemployed workers. This finding is in line with that of Balgova (2020), who shows that less educated US workers move less because they tend to work in sectors and occupations where cross-regional hiring is less commonplace, so that long-distance job search is more costly for them. However, as recently discussed by Amior (2019), this difference may also be driven by the fact that better-educated workers face more dispersed wage offers, hence larger surpluses.

The remainder of the paper is organized as follows. In section 1, we present our dataset and some descriptive statistics on the correlation between occupation and spatial mobility. Section 2 provides a short summary of the model, the identification strategy and the estimation method. In Section 3, we describe the estimation results and discuss linear decompositions of the local unemployment rate and average earnings. Section 4 provides a simulation framework aimed at quantifying the impact of differences in mobility costs and spatial frictions on the mobility gap between the two groups. Finally, Section 5 concludes.

\footnotetext{
they are less likely to be in an optimal match (Jovanovic, 1979). Moreover, as shown by Kennan and Walker (2011), age has a direct effect on mobility cost, for psychological reasons and reasons pertaining to homeownership status (Oswald, 2019).

${ }^{6}$ For example, Kennan and Walker (2011) focus on a sample of white males with a high-school education.

7This intuition was already present in Borjas, Bronars and Trejo (1992), who give reduced-form evidence that the search for a better return on education is the primary cause of internal migration in the US.

${ }^{8}$ Evidence on this is indirect. For example, on a longer time span than the one we consider, Diamond (2016) shows that skilled US workers are more sensitive to local amenities when choosing where to live and work, while the less skilled are more sensitive to housing prices and job opportunities.
} 


\section{Data and context}

\subsection{Dataset}

Regional migration is rare. In order to measure it accurately, we use the Panel DADS (Déclarations Annuelles de données sociales), a matched employer-employee panel dataset that has been widely used for the estimation of job search models since Postel-Vinay and Robin (2002). We restrict the panel to the 2002-2007 period, for which steady state assumptions seem to hold. ${ }^{9}$ This dataset documents the type of contract, the firm, the number of hours and days worked, the earned wage, as well as the place of work and place of residence at the municipality level. The main drawback of the DADS data is that it does not include a lot of individual information, besides age and occupation.

We make the same restrictions as Schmutz and Sidibé (2019): we only keep observations related to the main jobs of male workers who are always located in continental France over the period; we drop all individuals who were less than 15 years old or more than 58 years old at some point, to avoid confusion about participation decision; all workers who at some point were working in the public sector, as apprentice, from home or part time and all workers who at some point had a reported monthly wage below 900 euros or above 8,ooo euros; ${ }^{10}$ all individuals observed only once. We borrow calendar assumptions from Postel-Vinay and Robin (2002) in order to reconstruct underlying unemployment spells in this dataset.

Migration is defined as a change of workplace between two urban areas, which are good proxies of local labor markets (Moretti, 2011). ${ }^{11}$ Schmutz and Sidibé (2019) focus on the first 100 urban areas and end up with a panel of 384,114 individuals, featuring 2,073,705 observations. Given our focus on occupational heterogeneity, we need to further restrict the set of cities in order to maintain precision in the measurement of migration statistics. We therefore focus on the 30 largest urban areas, which make up for more than half of the French labor force. As shown in Figure A.I in Appendix A, they are scattered, although unevenly, all around the country. On average, our sample includes 4,066 blue-collar individuals and 2,522 white-collar individuals per city, with a minimum of 1,066 and 358. In Paris, these values reach 39,997 and 38,313 (against a total of 104,810 in Schmutz and Sidibé (2019)).

\subsection{Descriptive statistics}

Table 2 describes the main features of our dataset at the city level. Panel A shows that on average, blue-collar workers are twice more likely to be unemployed ( $15.6 \%$ against $7.5 \%)$ and they earn 2.3 times less when employed so their average expected income is at least 2.4 times lower ( $€_{15,244}$ against $€_{36,701)} .^{12}$ Unemployment risk is also much more varying across

\footnotetext{
9See Schmutz and Sidibé (2019) for details.

${ }^{10}$ The first case is considered as measurement error and the second case extends the support of wage distributions too dramatically for less than $1 \%$ of all individuals.

${ }^{11}$ Urban areas are defined using the functional definition of "aires urbaines", which are continuous clusters of municipalities with a main employment center of at least 5,000 jobs and a commuter belt composed of the surrounding municipalities with at least $40 \%$ of residents working in the employment center.

${ }^{12}$ Note that this gap is underestimated because it relies on the assumption of equal unemployment income, for lack of information on unemployment benefits in the DADS panel.
} 
cities for blue-collar workers, which shows that blue-collars would in theory benefit from the possibility of migration. However, as shown in Panel B, recorded migration is extremely low for this group: on average, white-collars are almost three times more mobile (0.8\% per year, against $0.29 \%)$. The gap is higher for unemployed workers, where the ratio is over $4(6.6 \%$ against $1.55 \%$ ) but it is also substantial for employed workers, even though mobility is quite low for both groups of employed workers.

Table 2: Labor market performance and mobility

Panel A: Unemployment and Income

\begin{tabular}{lcccccc}
\hline & \multicolumn{3}{c}{ Unemployment } & \multicolumn{2}{c}{ Mean wage } & \multicolumn{2}{c}{ Mean income } \\
& $\begin{array}{c}\text { Blue-c. } \\
(1)\end{array}$ & $\begin{array}{c}\text { White-c. } \\
(2)\end{array}$ & $\begin{array}{c}\text { Blue-c. } \\
(3)\end{array}$ & $\begin{array}{c}\text { White-c. } \\
\text { B }\end{array}$ & $\begin{array}{c}\text { Blue-c. } \\
(5)\end{array}$ & $\begin{array}{c}\text { White-c. } \\
(6)\end{array}$ \\
\hline $\begin{array}{l}\text { Unweighted } \\
\text { Mean }\end{array}$ & 14.16 & 8.68 & 16,615 & 37,495 & 15,129 & 34,766 \\
Standard deviation & 3.89 & 1.37 & 760 & 1,248 & 944 & 1,326 \\
Range & 12.79 & 4.85 & 2,827 & 6,620 & 3,387 & 6,191 \\
\hline Weighted by population & & & & & & \\
Mean & 15.60 & 7.45 & 16,950 & 39,158 & 15,244 & 36,701 \\
\hline
\end{tabular}

Panel B: Migration rate

\begin{tabular}{lcccccc}
\hline & \multicolumn{3}{c}{ Overall } & \multicolumn{2}{c}{ Unemployed } & \multicolumn{2}{c}{ Employed } \\
& $\begin{array}{c}\text { Blue-c. } \\
(1)\end{array}$ & $\begin{array}{c}\text { White-c. } \\
(2)\end{array}$ & $\begin{array}{c}\text { Blue-c. } \\
(3)\end{array}$ & $\begin{array}{c}\text { White-c. } \\
\text { B }\end{array}$ & $\begin{array}{c}\text { Blue-c. } \\
(5)\end{array}$ & $\begin{array}{c}\text { White-c. } \\
(6)\end{array}$ \\
\hline Unweighted & & & & & & \\
Mean & 0.35 & 1.15 & 1.95 & 8.55 & 0.08 & 0.47 \\
Standard deviation & 0.13 & 0.30 & 0.67 & 3.02 & 0.04 & 0.13 \\
Range & 0.46 & 1.41 & 2.82 & 12.61 & 0.19 & 0.64 \\
\hline Weighted by population & & & & & & \\
Mean & 0.29 & 0.80 & 1.55 & 6.60 & 0.08 & 0.31 \\
\hline
\end{tabular}

Notes: (i) Panel A: unemployment rate (\%), wage and unemployment-weighted income (using fixed unemployment allowance equal to €6,ooo); (ii) Panel B: yearly out-migration rate (\%) for the whole population and conditional on previous employment status; (iii) Statistics are weighted by the respective population of the two groups in the bottom sub-panels.

In order to dig deeper into this mobility gap, we then document the drivers of worker flows between cities. Table A.I displays the estimates of gravity equations of aggregate population flows between each city pair over geographic distance and a dissimilarity index based on the sectoral composition of the workforce between 35 sectors. ${ }^{13}$ Several results stand out: first, it is possible to explain over $50 \%$ of the variation in migration flows for both groups, thanks to the inclusion of city fixed effects. We will take advantage of this result in the estimation of the model - See Section 2.2. Second, in line with the results discussed by Schwartz (1973),

\footnotetext{
${ }^{13}$ We use the Duncan index: if $v$ is a categorical variable defined by categories $k$ in proportion $v_{j}(k)$ and $v_{l}(k)$ in cities $j$ and $l, h_{j l}=\sum_{k}\left|v_{j}(k)-v_{l}(k)\right|$. In order to construct this variable, we use the 2007 version of the firm level census database SIRENE.
} 
migration is strongly negatively correlated with distance for blue-collar workers, but only very weakly so for white-collar workers. Conversely, sectoral dissimilarity is negatively correlated with migration for both groups. Finally, controlling for quadratic terms shows that the effect of distance is convex for blue-collars, while the effect of dissimilarity is concave for both groups.

\section{Model and estimation}

\subsection{Model}

The model considers the steady-state behavior of risk-neutral workers who maximize in continuous time their discounted (at rate $r$ ) expected indirect utility. Within occupational groups, workers are ex ante identical and characterized by their labor market status $i=u$,e (unemployed or employed), their income $y=b, w$ (fixed allowance $b$ when unemployed and wage $w$ when employed) and their location $j$ (detailed below). We assume that occupational groups operate on fully separate labor markets and present a generic model suited for any group. ${ }^{14}$ Workers face posted wages and must decide whether or not to accept the offers they receive. The labor market is a set $\mathcal{J}$ of $J$ local labor markets (cities) $j$ with $\mathcal{J}_{j}=\mathcal{J}-\{j\}$ and there is a fixed number of workers in the economy. The distance between cities is considered as exogenous, but the total population $m_{j}$ and the number of unemployed $u_{j}$ at city level are determined by the job search process. Job offers follow a $F_{j}($.$) distribution of sup-$ port $[\underline{w}, \bar{w}] \subset[b ;+\infty[$ which results from the (exogenous) strategy of the firms. The resulting observed distribution of earnings is denoted $G_{j}($.$) .$

Cities are heterogeneous in terms of labor market characteristics and an amenity parameter $\gamma_{j}$ which enters linearly in workers' indirect utility $y+\gamma_{j}$. This parameter can be interpreted as the average valuation of the city $j$ among workers, net of local costs. This parameter is a spatial equilibrium object that makes it possible to rationalize why unemployed people do not all move to cities in which labor market conditions are better. Therefore, migration only occurs upon finding and accepting a new job. Workers receive job offers when they are unemployed as well as when they are employed. The flow of job offers depends on the worker's employment status, her location, and the location of the job offer. A type- $i$ worker in city $j$ receives local offers at rate $\lambda_{j}^{i}$. When the offer emanates from another city $l \neq j$, this rate is equal to $s_{j l}^{i} \lambda_{l}^{i} \leq \lambda_{l}^{i}$. It is lower than the local rate because of spatial frictions which reduce workers' ability to hear about or apply to remote job opportunities. In addition, if workers want to move from city $j$ to city $l$, they face a lump-sum mobility cost $c_{j l}$, independent of past employment status. Finally, employed workers in city $j$ face a $\delta_{j}$ job destruction rate. As explained above, when they become unemployed, they remain in city $j$.

Let $(x)^{+}=\max \{0, x\}$. With the convention that $s_{j j}^{i}=1$ and $c_{j j}=0$, the respective value functions of unemployed workers living in city $j$ and of workers employed in city $j$ and

\footnotetext{
${ }^{14}$ Contrary to Schmutz and Sidibé (2019), we consider two groups of occupations. Our assumption is that these occupations are different enough so that workers operate on separate labor markets and the model can be separately estimated on the two groups. This strategy is the same as in Postel-Vinay and Robin (2002), who use seven occupational categories separately, even if almost $20 \%$ of workers change categories over their recording period. In practice, we use a coarser partition into three groups and focus on the two polar categories, for which there is virtually no overlap (Monso, 2006).
} 
receiving a wage $w$ may be written as:

$$
\begin{aligned}
r V_{j}^{u} & =b+\gamma_{j}+\sum_{k \in \mathcal{J}} s_{j k}^{u} \lambda_{k}^{u} \int_{\underline{w}}^{\bar{w}}\left(V_{k}^{e}(x)-c_{j k}-V_{j}^{u}\right)^{+} d F_{k}(x) \\
r V_{j}^{e}(w) & =w+\gamma_{j}+\sum_{k \in \mathcal{J}} s_{j k}^{e} \lambda_{k}^{e} \int_{\underline{w}}^{\bar{w}}\left(V_{k}^{e}(x)-c_{j k}-V_{j}^{e}(w)\right)^{+} d F_{k}(x)+\delta_{j}\left[V_{j}^{u}-V_{j}^{e}(w)\right]
\end{aligned}
$$

The decision to accept or not to accept a job offer results from a trade-off between the expected income in the current city and the expected income in another city. This depends on the different parameters that are specific to cities and individual situations. These decisions depend on future prospects in the city under consideration. For example, it may be rational for a worker to accept a pay cut in another city which offers better career opportunities. Wageaccepting strategies are formalized by a reservation wage $\phi_{j}$ such that $V_{j}^{u}=V_{j}^{e}\left(\phi_{j}\right)$ and by a mobility-compatible indifference wage function $q_{j l}(w)$ verifying $V_{j}^{e}(w)=V_{l}^{e}\left(q_{j l}(w)\right)-c_{j l}$.

\subsection{Estimation}

The model is solved under steady state conditions on population $m_{j}$, unemployment rate $u_{j} / m_{j}$, and earning distribution $G_{j}($.$) , under a non-congestion condition whereby$ $\max _{l \in \mathcal{J}_{j}}\left\{V_{j}^{u}-V_{l}^{u}\right\}=c_{j l}$ that pins down amenity values $\gamma_{j}$ - See Appendix B for details. We seek to identify the set $\theta=\left\{\lambda_{j}^{i}, \delta_{j}, s_{j l}^{i}, c_{j l}\right\}$. The challenge is to identify the parameters separately and in particular, to distinguish between spatial frictions and mobility costs. The method used to identify them separately is to identify mobility costs via wage data and calculated indifference wages $q_{j l}($.$) , and to identify friction parameters with transition data between$ urban areas - See Proposition 1 in Schmutz and Sidibé (2019). Because of the structure of the model, it is possible to do so by constructing a piecewise linear approximation of the $q_{j l}($. thanks to an embedded sequential algorithm.

The model is estimated through the simulated method of moments. Equation 3 shows the function to minimize:

$$
\mathbf{L}(\theta)=(\hat{m}-m(\theta))^{T} \hat{W}^{-1}(\hat{m}-m(\theta))
$$

where $\hat{m}-m(\theta)$ is the difference between theoretical and empirical moments, which are described in table A.2. The matrix $\hat{W}$ is the diagonal of the estimated covariance matrix of $\hat{m}$. In order to alleviate the computational burden, we make three parametric approximations: first, wage offer distributions are parameterized as beta distributions. However, with 30 cities, the model still assumes almost 3,00o parameters. Therefore, we follow Schmutz and Sidibé (2019) and use simple parametric models where spatial frictions and mobility costs depend on the distance and the sectoral dissimilarity between city pairs. The cost parametrization is a simple quadratic equation of these two dimensions, while spatial frictions are modeled as a logistic function of distance and dissimilarity as well as two city fixed effects (as origin or destination of the flows) - See Equations 4 and 5 in Appendix B for details. With these approximations, the number of parameters to estimate amounts to 278 per group. 


\subsection{Fit}

We set unemployment income $b=€ 6$,ooo annually (an approximation of the minimum guaranteed income, which amounts to about half of the minimum wage) and $r=2 \%$. The minimum wage is set to $€_{10,874}$ annually. The model is optimized using sequentially derivative free optimization techniques. Integrals are evaluated numerically using trapezoidal integration rule. Standard deviations are obtained by bootstrap. The fit of the model is good: as shown in Figure A.2 in Appendix A, we can predict local unemployment rates fairly accurately, even though they are not explicitly targeted in the estimation. The correlation between predicted unemployment and observed unemployment is over $90 \%$ for blue-collars and close to $80 \%$ for white-collars.

\section{Results}

\subsection{Local labor markets}

Table 3 provides summary statistics of the city-specific matching parameters. Values are given in yearly terms. Differences between the two groups are substantial, as first documented by Postel-Vinay and Robin (2002). On average, blue-collar jobs are destroyed every six years, against 11 years for white-collar jobs (columns (5) and (6)). This difference explains the bulk of the group difference in unemployment rates (14.2\% against $8.7 \%$ ). The estimated values of $\lambda_{j}^{u}$ show substantial heterogeneity across cities, especially for white-collars for whom values span from 0.85 to 1.95 , suggesting city average unemployment durations from 6 to 14 months in the absence of migration (column (2)). The group mean values of 0.56 and 1.24 confirm the low transition rate in France as documented by Jolivet, Postel-Vinay and Robin (2006), especially for blue-collar workers. This job arrival rate gap is all the more important that white-collar workers are over-represented in cities with high job arrival rates, as shown in the bottom panel.

Table 3: City-specific parameters: summary statistics.

\begin{tabular}{lcccccc}
\hline & \multicolumn{2}{c}{$\lambda_{j}^{u}$} & \multicolumn{2}{c}{$\lambda_{j}^{e}$} & \multicolumn{2}{c}{$\delta_{j}$} \\
& $\begin{array}{c}\text { Blue-c. } \\
(1)\end{array}$ & $\begin{array}{c}\text { White-c. } \\
(2)\end{array}$ & $\begin{array}{c}\text { Blue-c. } \\
(3)\end{array}$ & $\begin{array}{c}\text { White-c. } \\
(4)\end{array}$ & $\begin{array}{c}\text { Blue-c. } \\
(5)\end{array}$ & $\begin{array}{c}\text { White-c. } \\
(6)\end{array}$ \\
\hline $\begin{array}{l}\text { Unweighted } \\
\text { Mean }\end{array}$ & & & & & & \\
Standard deviation & 0.575 & 1.236 & 0.030 & 0.115 & 0.167 & 0.090 \\
Range & 0.068 & 0.226 & 0.003 & 0.008 & 0.022 & 0.019 \\
\hline Weighted by population & 0.255 & 1.104 & 0.012 & 0.129 & 0.084 & 0.122 \\
Mean & & & & & & \\
Standard deviation & 0.545 & 1.653 & 0.032 & 0.128 & 0.172 & 0.107 \\
\hline
\end{tabular}

Notes: (i) Yearly values of the matching parameters; (ii) Each distribution is evaluated on 30 cities. (iii) Statistics are weighted by the respective population of the two groups in the bottom panel. 
Estimates for $\lambda_{j}^{e}$ are substantially lower than for $\lambda_{j}^{u}$ : the ratio between the two means is larger than 15 for blue-collars and larger than 10 for white-collars. It is nevertheless twice higher than what Schmutz and Sidibé (2019) find, which is not surprising because we focus on the 30 largest cities (instead of the 10o largest) where on-the-job search is more frequent. Contrary to Postel-Vinay and Robin (2002), who acknowledge that their result is somewhat surprising, we also find substantial group differences in job arrival rates for employed workers. In relative terms, the gap between blue-collars and white-collars is even larger than for unemployed workers, with a one-to-four difference.

\subsection{Spatial constraints}

We now quantify spatial constraints using our parameter estimates, starting with mobility costs. On average, these costs are equal to $€_{14,938}$ for white-collar workers and $€_{14,635}$ for blue-collar workers, which is quite close to the average value found by Schmutz and Sidibé (2019): as argued by the authors, these costs are much lower than the average individual value estimated by Kennan and Walker (2011), who do not take the frictional aspect of job search into account. Second, even if the wage distributions used to identify mobility costs are very different for the two occupational groups, resulting estimates are strikingly similar, in line with evidence on self-reported willingness to move described by Amior (2019). A priori, white-collar workers could face higher relocation costs if they are more likely to own their home or to belong to a double-income household; on the other hand, low-skilled workers are more likely to rely on informal, location-specific networks in their daily lives and to live in public housing. ${ }^{15}$

However, this nominal value is not fully informative of the relative importance of mobility costs for the two groups. In columns (1) and (2) in Table 4, we contrast the average mobility cost to the average unemployment-weighted income in the origin city. Given blue-collars are more likely to be unemployed and earn less when employed, their average income is more than twice lower than that of white-collar workers. This results in a mobility cost to income ratio that is on average equal to one-third for white-collars, while it is close to unity for blue-collar workers. In order to evaluate the impact of mobility costs on mobility, Section 4.1 will provide simulation results from a counterfactual population of blue-collar workers facing mobility costs divided by three.

We then discuss the relative magnitude of local job arrival rates and remote job arrival rates, for a given worker. Table 4 shows the distribution of the ratios of local job finding rate to the migration rates for both unemployed (columns (3) and (4)) and employed (columns (5) and (6)) workers, that is, by which factor local job arrival rates would need to be raised to offset a hypothetical situation where workers would no longer be able to migrate to other cities. The gap is much more pronounced between occupations than between employment status: remote job offers account for $2 \%$ of job offers accruing to blue-collar workers, against more than $5 \%$ for white-collars. ${ }^{16}$ In order to evaluate the impact of spatial frictions on mobility, Section 4.2

\footnotetext{
${ }^{15}$ According to the 2006 National Housing Survey, 72\% of white-collars own their home against $43 \%$ for bluecollar workers; for public housing, the shares are $6 \%$ and $29 \%$ respectively.

${ }^{16}$ If anything, blue-collar unemployed workers are less connected to other cities than their employed coun-
} 
will provide simulation results from a counterfactual population of blue-collar workers facing the same level of frictions $s_{j l}^{i}$ as white-collars.

Table 4: Spatial constraints

\begin{tabular}{|c|c|c|c|c|c|c|}
\hline & \multicolumn{2}{|c|}{$\begin{array}{l}\text { Mobility cost to } \\
\text { average income ratio }\end{array}$} & \multicolumn{4}{|c|}{$\begin{array}{c}\text { Ratio of between-to within-city job arrival } \\
\text { Unemployed }\end{array}$} \\
\hline & $\begin{array}{l}\text { Blue-c. } \\
\text { (1) }\end{array}$ & $\begin{array}{l}\text { White-c. } \\
\text { (2) }\end{array}$ & $\begin{array}{c}\text { Blue-c. } \\
\text { (3) }\end{array}$ & $\begin{array}{c}\text { White-c. } \\
\text { (4) }\end{array}$ & $\begin{array}{c}\text { Blue-c. } \\
\text { (5) }\end{array}$ & $\begin{array}{l}\text { White-c. } \\
\text { (6) }\end{array}$ \\
\hline \multicolumn{7}{|l|}{ Unweighted } \\
\hline Mean & 0.93 & 0.36 & 0.019 & 0.065 & 0.024 & 0.056 \\
\hline Standard deviation & 0.06 & 0.01 & 0.008 & 0.021 & 0.031 & 0.033 \\
\hline \multicolumn{7}{|l|}{ Weighted by population } \\
\hline Mean & 0.92 & 0.35 & 0.013 & 0.048 & 0.017 & 0.028 \\
\hline Standard deviation & 0.05 & 0.01 & 0.010 & 0.017 & 0.025 & 0.036 \\
\hline
\end{tabular}

Notes: (i) Columns (1) and (2): ratio of the average mobility cost to the unemployment-weighted average income in the origin city: $\sum_{k \in \mathcal{J}_{j}} c_{j k} /\left[\bar{y}_{j}(J-1)\right]$ with $\bar{y}_{j}=u_{j} b+\left(1-u_{j}\right) \bar{w}_{j}$ and $\bar{w}_{j}$ average wage; (ii) Columns (3) to (6): ratio of between-city to within-city job arrival rates: it is equal to $\sum_{k \in \mathcal{J}_{j}} s_{j k}^{u} \lambda_{k}^{u} / \lambda_{j}^{u}$ in columns (3) and (4) and to $\sum_{k \in \mathcal{J}_{i}} s_{j k}^{e} \lambda_{k}^{e} / \lambda_{j}^{e}$ in columns (5) and (6); (iii) The distribution is evaluated on 30 cities. (iv) Statistics are weighted by the respective population of the two groups in the bottom panel.

\subsection{Decompositions}

We use our estimated parameters to assess their relative impact on the two main measures of labor market performance: the unemployment rate and the level of earnings, using simple linear regression models. In Table 5, we look at the relative impact of the parameters that come into the structural definition of the local unemployment rate $u_{j} / m_{j}=\delta_{j} /\left(\delta_{j}+\sum_{k \in \mathcal{J}} s_{j k}^{u} \lambda_{k}^{u}\right)$. The first takeaway is that while blue-collar workers' unemployment is very well explained by the job destruction rate, this is not the case for white-collar workers (columns (1) and (4)). This confirms the well-known fact that blue-collar workers are more sensitive to macroeconomic fluctuations. Second, columns (2) and (5) show that the unemployment rate is almost entirely explained by local parameters $\delta_{j}$ and $\lambda_{j}^{u}$. This does not come as a surprise, given the low relative magnitude of arrival rates for jobs located in other cities described in Table 4. However, white-collar workers' unemployment rate is strongly negatively correlated with their ability to receive job offers from other cities. Increasing the compound rate of remote job offers by one standard deviation is associated with a decrease of 0.11 standard deviation of the unemployment rate for these workers, while the effect is a precise zero for blue-collar workers (columns (3) and (6)).

We then turn to the correlation between our estimates and the average level of earnings in each city. This exercise is not as straightforward as the previous one because earnings are a more complex outcome in our model and we choose to use observed earning as a first pass.

terparts, while the opposite is true for white-collar workers. Note that, since white-collar workers are overrepresented in cities with high job arrival rates, the difference between the two groups is lowered for employed workers in the aggregate, as shown in the bottom panel. 
Table 5: Decomposition of the local unemployment rate

\begin{tabular}{lcccccc}
\hline & \multicolumn{3}{c}{ Blue-collar unemployment } & \multicolumn{3}{c}{ White-collar unemployment } \\
& $(1)$ & $(2)$ & $(3)$ & $(4)$ & $(5)$ & $(6)$ \\
\hline$\delta_{j}$ & $0.900^{* * *}$ & $0.562^{* * *}$ & $0.563^{* * *}$ & $0.675^{* *}$ & $1.001^{* * *}$ & $0.971^{* * *}$ \\
& $(0.081)$ & $(0.019)$ & $(0.020)$ & $(0.257)$ & $(0.012)$ & $(0.016)$ \\
$\lambda_{j}^{u}$ & & $-0.548^{* * *}$ & $-0.547^{* * *}$ & & $-0.795^{* * *}$ & $-0.758^{* * *}$ \\
& & $(0.024)$ & $(0.026)$ & & $(0.052)$ & $(0.023)$ \\
$\sum_{k \in \mathcal{J}_{j}} s_{j k}^{u} \lambda_{k}^{u}$ & & & -0.007 & & & $-0.114^{* * *}$ \\
& & & $(0.014)$ & & & $(0.021)$ \\
\hline R-squared & 0.810 & 0.996 & 0.996 & 0.455 & 0.981 & 0.993 \\
\hline
\end{tabular}

Notes: (i) OLS regressions of the estimated local unemployment rate on the structural parameters; (ii) All variables are standardized and a constant term is included; (iii) Robust standard errors in parentheses; (iv) ${ }^{* * *}$ and ${ }^{* * *}$ respectively denote significance at the $90 \%, 95 \%$ and $99 \%$ confidence levels; (v) The R-squared does not max at 100\% because other parameters come into the definition of indifference wages.

In addition to structural parameters, we control for the observed level of unemployment and the size of the group. As shown in Table 6, our findings are once again threefold. First, as expected, the average level of wage offers is a strong determinant of the average level of earnings. Yet, the correlation is much stronger for blue-collar workers (columns (1) and (4)), who are more dependent on single offers given they do not experience a lot of job-to-job mobility.

Table 6: Decomposition of local average earnings

\begin{tabular}{lcccccc}
\hline & \multicolumn{3}{c}{ Blue-collar average wage } & \multicolumn{3}{c}{ White-collar average wage } \\
& $(1)$ & $(2)$ & $(3)$ & $(4)$ & $(5)$ & $(6)$ \\
\hline $\int_{\underline{w}}^{\bar{w}} x d F_{j}(x)$ & $0.849^{* * *}$ & $0.864^{* * *}$ & $0.861^{* * *}$ & $0.448^{* * *}$ & $0.477^{* * *}$ & $0.470^{* * *}$ \\
& $(0.145)$ & $(0.076)$ & $(0.084)$ & $(0.140)$ & $(0.127)$ & $(0.130)$ \\
Unemployment rate & & $-0.406^{* * *}$ & $-0.410^{* * *}$ & & -0.149 & -0.168 \\
& & $(0.054)$ & $(0.084)$ & & $(0.153)$ & $(0.147)$ \\
Population & & $-0.157^{* * *}$ & $-0.152^{*}$ & & $0.473^{* * *}$ & $0.596^{* * *}$ \\
& & $(0.053)$ & $(0.075)$ & & $(0.063)$ & $(0.147)$ \\
$\lambda_{j}^{e}$ & & & -0.0241 & & & -0.0719 \\
$\sum_{k \in \mathcal{J}_{j}} s_{j k}^{e} \lambda_{k}^{e}$ & & & $(0.172)$ & & & $(0.203)$ \\
& & & 0.0248 & & & $0.311^{* *}$ \\
\hline R-squared & & & $(0.169)$ & & & $(0.116)$ \\
\hline
\end{tabular}

Notes: (i) OLS regressions of the observed local level of earnings on the average wage offers, unemployment rate, population and on-the-job search parameters; (ii) All variables are standardized and a constant term is included; (iii) Robust standard errors in parentheses; (iv) ${ }^{* * *}$ and ${ }^{* * *}$ respectively denote significance at the $90 \%, 95 \%$ and $99 \%$ confidence levels. 
Second, the correlation with population size and unemployment is very different between the two groups: blue-collar workers earn slightly less in larger cities while white-collars earn much more in larger cities; moreover, blue-collars earn much less when they face a high unemployment risk, which makes them more likely to work for the minimum wage, while whitecollars' wages are virtually unaffected, because employed white-collar workers are much less likely to have directly transitioned from unemployment. Finally, job arrival rates for employed workers are not correlated with average wages for blue-collar workers but are positively correlated with wages for white-collar workers, at least for remote job offers (columns (3) and (6)). Controlling for on-the-job search has a non-trivial impact on the explanatory power of the model for this group (the R-squared raises from $49 \%$ up to $59 \%$ ) while it has zero impact for blue-collars. However, the wage of blue-collars is very well explained by the model, while this is not the case for white-collars.

In order to test our modeling assumption that the two occupations operate on separate labor markets, we perform placebo decompositions where the local unemployment rate and the local average wage are regressed on the other group's parameters. Results are displayed in Tables A.3 and A.4 in Appendix C. For predicted unemployment, the R-squared maxes at $7 \%$ for blue-collars and $5 \%$ for white-collars, while it was $99 \%$ in Table 5 . For observed wages, results are more mixed, at least for white-collars: their wage is positively correlated with the average wage offered to blue-collar workers. However, the correlation tends to break down when we control for other characteristics. As for blue-collars' on-the-job search parameters, they are only weakly correlated with white-collars' wages.

\section{Simulations}

Spatial constraints are much higher for blue-collar workers but the previous decompositions do not seem to indicate that blue-collars' labor market performance is impacted by them. In this section, we take advantage of our empirical setting to study the impact of two policies targeted towards blue-collar workers on their mobility. We simulate forward a system of cities where a population of 100,000 agents work for 5, 10 or 20 years and we compute the resulting average mobility rate. This simulation is an imperfect way of performing counterfactual experiments given our partial equilibrium assumption whereby matching rates and wage offer distributions are exogenous, and our steady state assumption.

\subsection{Subsidizing relocation}

We first focus on the most straightforward policy tool: relocation subsidies. We simulate the mobility of blue-collar workers if those faced mobility costs equal to a third of what they actually are: $\tilde{c}_{j l}[$ blue-collar $]=c_{j l}[$ blue-collar $] / 3$ : that way, they roughly represent the same relative financial burden as for white-collars, as documented in Table 4. We leave the question of financing aside. The policy may be implemented on unemployed workers, on employed workers or on both. Schmutz and Sidibé (2019) show that lowering relocation costs has a small absolute impact on the mobility rate: in their simulations, setting the cost to zero only 
increases the yearly mobility rate by $5 \%$ and the bulk of the effect is driven by unemployed workers.

Results are presented in Panel A in Table 7. The first take-away is that, similar to Schmutz and Sidibé (2019), we find little effect of relocation subsidies on the migration rate. If the policy is implemented for 5 years, blue-collars' migration rate increases by $10 \%$ if costs are subsidized both for unemployed and employed workers. The effect is fairly large for employed workers, but their initial mobility level is very low compared to that of unemployed workers (see Table 2). In addition, this increased mobility comes at the cost of a lower mobility for unemployed workers, who suffer from competition of more mobile employed workers. ${ }^{17}$ Contrary to Schmutz and Sidibé (2019), we find that specifically targeting unemployed workers is not more efficient: the mobility of unemployed workers is only weakly positively affected, and the overall effect is virtually zero. Blue-collar unemployed workers cannot be made more mobile with relocation subsidies, because, as argued by Amior (2019), their prospects are not much better elsewhere, contrary to other types of unemployed workers.

Table 7: Simulation results: impact on blue-collars' migration rate

Panel A: Subsidizing mobility costs

\begin{tabular}{lccccccccc}
\hline & \multicolumn{3}{c}{5 -year policy } & \multicolumn{3}{c}{ 10-year policy } & \multicolumn{3}{c}{20 -year policy } \\
Targeted group & $e, u$ & $e$ & $u$ & $e, u$ & $e$ & $u$ & $e, u$ & $e$ & $u$ \\
\hline Overall & $10 \%$ & $10 \%$ & $-0 \%$ & $+3 \%$ & $+5 \%$ & $-2 \%$ & $+1 \%$ & $+4 \%$ & $-5 \%$ \\
Employed & $+41 \%$ & $+44 \%$ & $-0 \%$ & $+29 \%$ & $+35 \%$ & $+7 \%$ & $+21 \%$ & $+31 \%$ & $-12 \%$ \\
Unemployed & $-4 \%$ & $-4 \%$ & $+0 \%$ & $-8 \%$ & $-8 \%$ & $+0 \%$ & $-9 \%$ & $-8 \%$ & $-2 \%$ \\
\hline
\end{tabular}

Panel B: Lowering spatial frictions

\begin{tabular}{lccccccccc}
\hline & \multicolumn{3}{c}{5 -year policy } & \multicolumn{3}{c}{ 10-year policy } & \multicolumn{3}{c}{ 20-year policy } \\
& $e, u$ & $e$ & $u$ & $e, u$ & $e$ & $u$ & $e, u$ & $e$ & $u$ \\
\hline Overall & $+10 \%$ & $+8 \%$ & $+3 \%$ & $+25 \%$ & $+18 \%$ & $+8 \%$ & $+51 \%$ & $+35 \%$ & $+16 \%$ \\
Employed & $+27 \%$ & $+25 \%$ & $+2 \%$ & $+53 \%$ & $+49 \%$ & $+6 \%$ & $+96 \%$ & $+83 \%$ & $+12 \%$ \\
Unemployed & $+4 \%$ & $+1 \%$ & $+3 \%$ & $+13 \%$ & $+5 \%$ & $+9 \%$ & $+31 \%$ & $+13 \%$ & $+18 \%$ \\
\hline
\end{tabular}

Notes: (i) Evolution of the overall migration rate (first row) and of the migration rate of employed (second row) or unemployed (third row) workers; (ii) Values are expressed in \% changes compared to benchmark values; (iii) Panel A: mobility costs are divided by three for all workers (column $e, u$ ), employed workers (column $e$ ) and unemployed workers (column $u$ ); (iv) Panel B: spatial frictions are set to white-collars' values for all workers (column $e, u$ ), employed workers (column $e$ ) and unemployed workers (column $u$ ).

The second result from our simulations is novel: we show that the impact of relocation subsidies becomes negative over time: over 1o years, the mobility rate increases by $3 \%$, and over 20 years, by $1 \%$. This counter-intuitive result may be explained as follows: the economy in these simulations is no longer operating at steady state and the short-run impact of relocation subsidies is to allow workers initially located in well-integrated cities to take on job offers located in peripheral cities. However, once they live there, it becomes impossible for them

\footnotetext{
17This effect was already noted in Schmutz and Sidibé (2019).
} 
to move back again. As shown in Table 4, mobility costs vary very little between cities: the bulk of the cost is a fixed component, while this is not the case of spatial frictions, which are very different across cities. This explains why, over 20 years, a policy specifically targeting unemployed workers has a negative impact on their mobility $(-2 \%)$.

\subsection{Lowering spatial frictions}

Since relocation subsidies may backfire in the presence of high spatial frictions for blue-collar workers, we compare their effects to the effect of exposing blue-collar workers to the same level of spatial frictions as white-collars: $\tilde{s}_{j l}^{i}[$ blue-collar $]=s_{j l}^{i}[$ white-collar $] .{ }^{18}$ Results are presented in Panel B of Table 7. Over a short time span ( 5 years), both policies seem to have the same effect (a 10\% increase) on the migration rate. However, this increase is more evenly split between employed and unemployed workers. More importantly, this policy does not backfire over time, because it increases blue-collars' ability to move from any city. After 1o years, yearly migration has increased by $25 \%$, and after 20 years, by $51 \%$ (results are fairly stable after 20 years). This suggests that if faced with the same spatial search frictions as white-collar workers, blue-collar workers who are on average three times less mobile than white-collar workers, would end up with a migration rate that would only be twice as low.

\section{Conclusion}

In this paper, we use a dynamic model of job-related migration to quantify the impact of mobility costs and spatial frictions on the mobility gap between blue-collar and white-collar workers, controlling for differential return to migration. We show that blue-collar workers face mobility costs that are three times higher when compared to their average income and that they are at least twice less connected to other cities than white-collar workers. Given these high spatial constraints, blue-collars are far less mobile and their unemployment level and their level of wages are virtually unaffected by their ability to search for jobs in other cities. Simulations show that if they faced the same spatial search frictions as white-collars, their mobility rate would only be twice, instead of three times, lower. However, implementing such a policy is not straightforward, in particular given it is much less efficient when only targeted toward unemployed workers. Conversely, the most straightforward mobility policy, relocation subsidies, may have adverse effects, by providing incentives to locate in poorly connected local labor markets.

\footnotetext{
${ }^{18}$ There is no obvious way of implementing such a policy, except better integration of local unemployment agencies for blue-collar workers. In addition, this type of counterfactual exercise is more dicey than the previous one because it is likely to have larger equilibrium effects on local job arrival rates. Schmutz and Sidibé (2019) only simulate a counterfactual situation of autarky, where spatial frictions are assumed to be infinite.
} 


\section{References}

Amior, Michael, "Education and Geographical Mobility: The Role of the Job Surplus," CEP Discussion Papers dp1616, Centre for Economic Performance, LSE May 2019.

Balgova, Maria, "Leaping into the unknown? The role of job search in migration decisions," Technical Report, Working paper, Oxford University (updated version) 2020.

Borjas, George J, Stephen G Bronars, and Stephen J Trejo, "Self-selection and internal migration in the United States," Journal of urban Economics, 1992, 32 (2), 159-185.

Bryan, Gharad and Melanie Morten, "The aggregate productivity effects of internal migration: evidence from Indonesia," Journal of Political Economy, 2018.

Burda, Michael C and Stefan Profit, "Matching across space: Evidence on mobility in the Czech Republic," Labour Economics, 1996, 3 (3), 255-278.

Dahl, Gordon B, "Mobility and the return to education: Testing a Roy model with multiple markets," Econometrica, 2002, 70 (6), 2367-2420.

Diamond, Rebecca, "The determinants and welfare implications of us workers' diverging location choices by skill: 1980-2000," American Economic Review, 2016, 106 (3), 479-524.

Flinn, Christopher and James Heckman, "New methods for analyzing structural models of labor force dynamics," Journal of Econometrics, 1982, 18 (1), 115-168.

Gallin, Joshua Hojvat, "Net migration and state labor market dynamics," Journal of Labor Economics, 2004, 22 (1), 1-21.

Greenwood, Michael J, "Internal migration in developed countries," Handbook of population and family economics, 1997, 1, 647-720.

Head, Keith and Thierry Mayer, "Gravity Equations: Workhorse,Toolkit, and Cookbook," in "Handbook of International Economics," Vol. 4, Elsevier, 2014, chapter Chapter 3, pp. 131195 .

Jolivet, Gregory, Fabien Postel-Vinay, and Jean-Marc Robin, "The empirical content of the job search model: Labor mobility and wage distributions in Europe and the US," European Economic Review, May 2006, 50 (4), 877-907.

Jovanovic, Boyan, "Job matching and the theory of turnover," Journal of political economy, 1979, 87 (5, Part 1), 972-990.

Kennan, John and James $\mathbf{R}$ Walker, "The effect of expected income on individual migration decisions," Econometrica, 2011, 79 (1), 211-251.

Manning, Alan and Barbara Petrongolo, "How local are labor markets? Evidence from a spatial job search model," American Economic Review, 2017, 107 (10), 2877-2907. 
McCall, John Joseph, "Economics of information and job search," The Quarterly Journal of Economics, 1970, pp. 113-126.

Monso, Olivier, "Changer de groupe social en cours de carrière," INSEE Premir̀e, 2006, 1112.

Moretti, Enrico, "Local Labor Markets," in Orley Ashenfelter and David Card, eds., Handbook of Labor Economics, Vol. 4, Part B, Elsevier, 2011, chapter Chapter 14, pp. 1237 - 1313.

Oswald, Florian, "The Effect of Homeownership on the Option Value of Regional Migration," forthcoming Quantitative Economics, 2019.

Postel-Vinay, Fabien and Jean-Marc Robin, “Equilibrium Wage Dispersion with Worker and Employer Heterogeneity," Econometrica, 2002, 70 (6), 2295-2350.

Schmutz, Benoit and Modibo Sidibé, "Frictional Labor Mobility," The Review of Economic Studies, 2019, 86 (4), 1779-1826.

Schwartz, Aba, "Interpreting the Effect of Distance on Migration," Journal of Political Economy, 1973, 81 (5), 1153-69.

Sjaastad, Larry A, "The costs and returns of human migration," Journal of political Economy, 1962, 70 (5, Part 2), 80-93. 


\section{Appendix}

\section{A Figures}

Figure A.1: The thirty largest urban areas in France

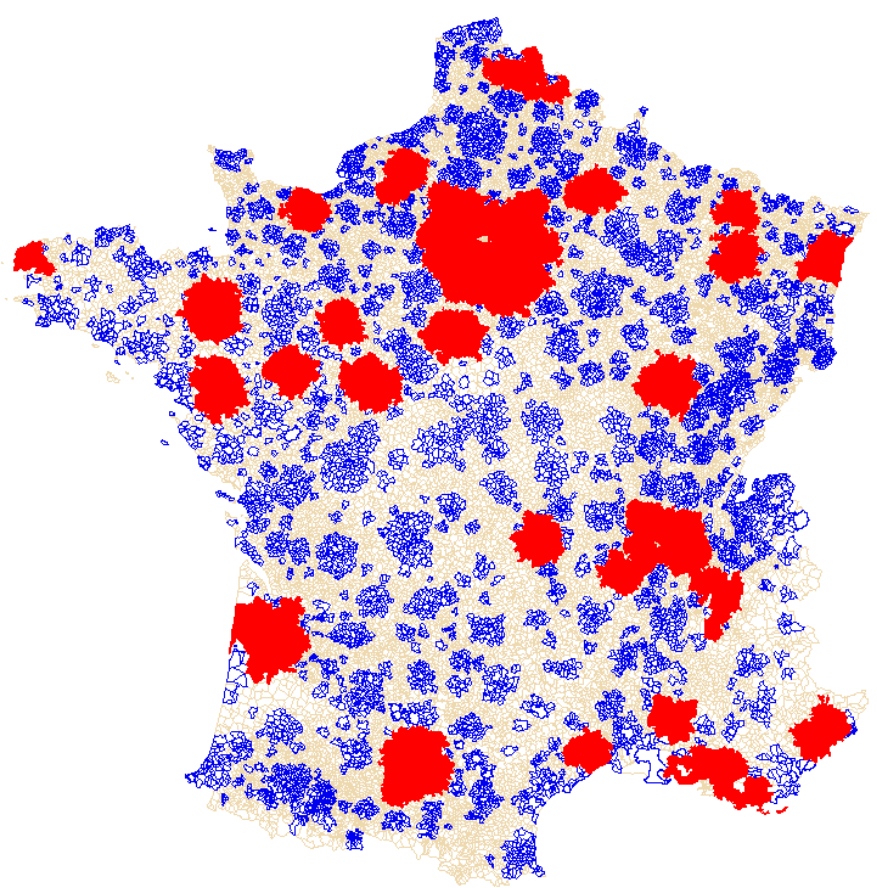

Notes: (i) Unit of observation: the municipality; (ii) darker borders: municipalities that belong to an urban area; (iii) darker filling: the thirty largest urban areas (over seven thousand municipalities); (iv) The thirtieth urban area is Brest.

Figure A.2: Fit: local unemployment rates
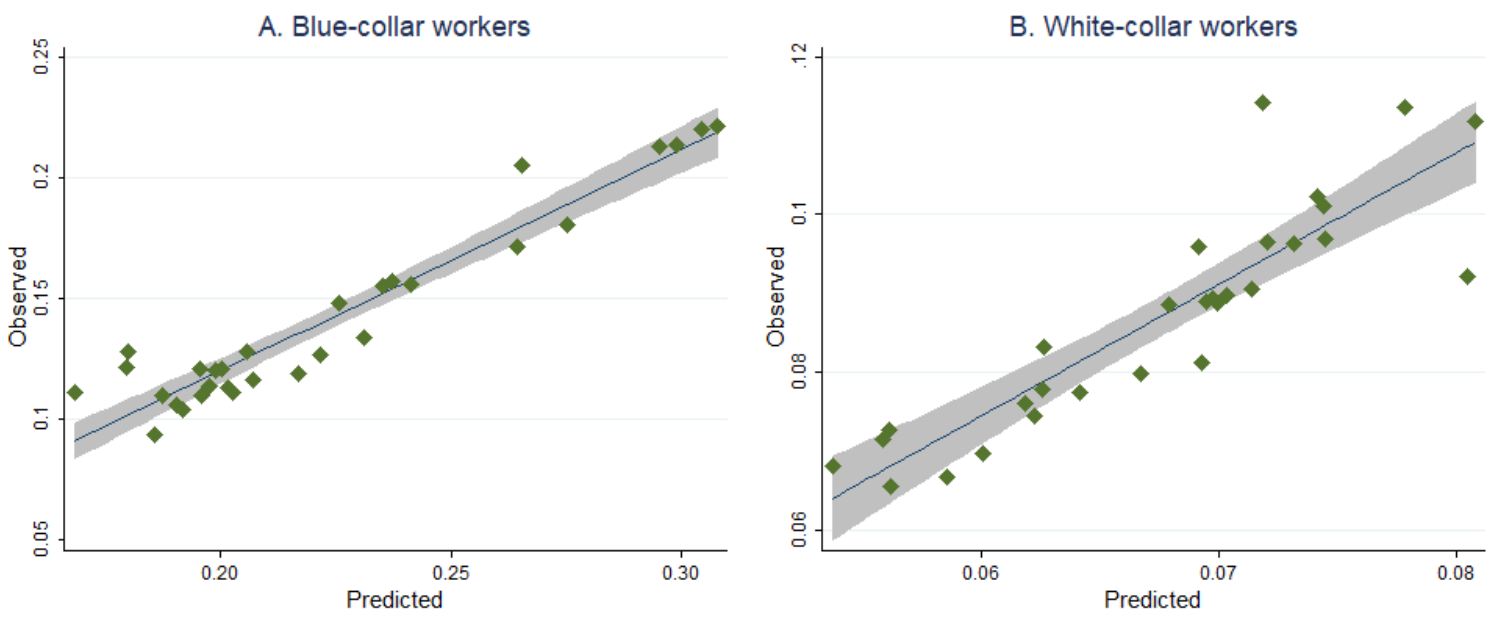

Notes: (i) Comparison of predicted and observed unemployment rates; (ii) The shaded area represents the $95 \%$ confidence interval of a bivariate regression using ordinary least squares; (iii) R-squared is equal to $91 \%$ for bluecollar workers and $79 \%$ for white-collar workers. 


\section{B Details on identification and estimation}

We seek to identify the set $\theta=\left\{\lambda_{j}^{i}, \delta_{j}, s_{j l}^{i}, c_{j l}\right\}$. The challenge is to identify the parameters separately and in particular to distinguish spatial frictions from mobility costs. The solution is to identify mobility costs via wage data and calculated indifference wages, and to identify friction parameters with transition data between cities. The intuition that indifference wages are identified by transition wages comes from the method presented by Flinn and Heckman (1982) to estimate reservation wages. In our case, the lowest indifference wage $q_{j, l}(\underline{w})$ can be estimated by the lowest accepted wage by those who have made the transition from $j$ to $l$ city from unemployment to employment. In order to identify the distribution of wage offers, it is necessary to assume that the observed wages are i.i.d and follow a stationary law, which makes it possible to establish, by applying Schauder's fixed point theorem, that there is a single mapping between the distribution of accepted wages $G_{j l}($.$) (observed) and$ the distribution of wage offers $F_{j}\left(q_{l j}().\right)$.

With 30 cities, the number of parameters to be estimated is very large (almost 3000 parameters per subgroup). In order to substantially reduce the computational burden, Schmutz and Sidibé (2019) follow Kennan and Walker (2011) and estimate the costs and friction parameters using simple parametric models:

$$
\begin{aligned}
s_{j l}^{i} & =\frac{\exp \left(s_{j 0}^{i}+s_{0 l}^{i}+s_{1}^{i} d_{j l}+s_{2}^{i} d_{j l}^{2}+s_{3}^{i} h_{j l}+s_{4}^{i} h_{j l}^{2}\right)}{1+\exp \left(s_{j 0}^{i}+s_{0 l}^{i}+s_{1}^{i} d_{j l}+s_{2}^{i} d_{j l}^{2}+s_{3}^{i} h_{j l}+s_{4}^{i} h_{j l}^{2}\right)} \\
c_{j l} & =c_{0}+c_{1} d_{j l}+c_{2} h_{j l}+c_{3} d_{j l}^{2}+c_{4} h_{j l}^{2}
\end{aligned}
$$

where $d_{j l}$ is the physical distance between city $j$ and city $l, h_{j l}$ is a measure of sectoral dissimilarity between city $j$ and city $l$. The model rests upon the premise that spatial friction parameters take on values in $[0,1]$, whereas the range of values for mobility costs is unrestricted. Given the lack of existing literature on the explicit structure of spatial frictions, we use a logistic function in Equation 4 because of its analytical properties. Equation 4 is akin to a standard gravity equation: the fixed effects measure the relative openness of the local labor markets: either the ability of each city to dispatch its jobseekers to jobs located elsewhere $\left(s_{j 0}\right)$ or to fill its vacancies with workers coming from other locations $\left(s_{0 l}\right)$, and the other parameters account for the effect of distance between two locations. ${ }^{19}$

Physical distance is arguably the most important characteristic and both equations 4 and 5 rely on it. As for sectoral dissimilarity, it is used in order to reflect human capital specificity, which may be of particular importance to rationalize, for instance, job-to-job mobility rates between highly specialized but distant cities, between which workers will be likely to move because they will a good fit for local production needs (Bryan and Morten, 2018). We introduce a second-order polynomial to capture more flexible effect of distance on these rates. Gravity estimates on migration flows are displayed in Table A.1. Note that, in order to ensure continuity at the reservation wage, we assume that moving costs do not vary with labor market status, unlike spatial frictions.

\footnotetext{
${ }^{19}$ See Head and Mayer (2014) for the current state of the art about gravity equations.
} 


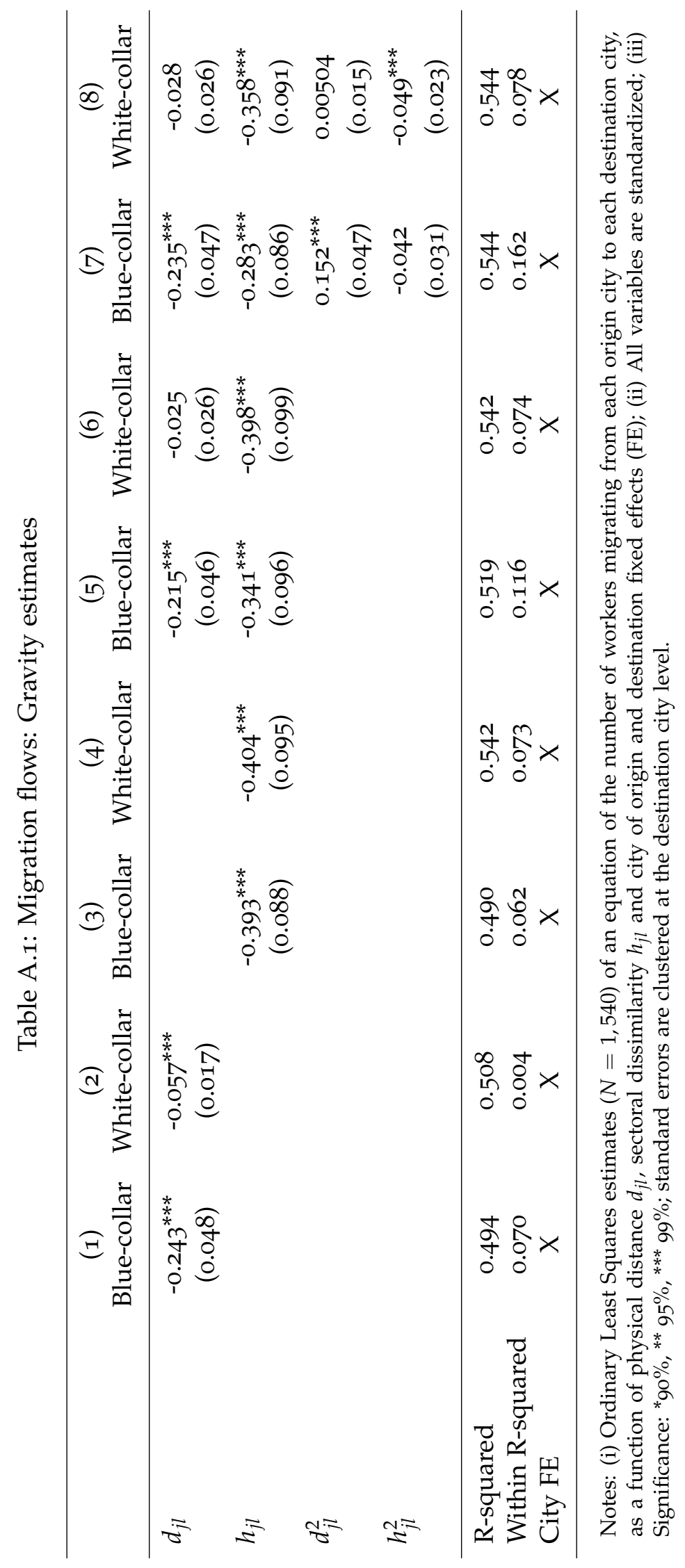


Given this parameterization, the model is over-identified. In order to identify the fixedeffect components, we use the $2(J-1)$ total transitions rates into and out of any given city. On the other hand, the identification of the parameters related to the distance and the dissimilarity between two cities still requires transition rates at the city-pair level. Given that Equation 4 only specifies four parameters for each labor market status, we drastically restrict the set of city pairs, down to a subset $\mathcal{T}_{1} \subset \mathcal{J} \times \mathcal{J}_{j}$. While spatial friction parameters are identified off of transition rates between pairs of cities, mobility costs are identified from data on wages. Given there only are five parameters to estimate, we select a subset of city pairs $\mathcal{T}_{2}$. This subset is more restrictive than $\mathcal{T}_{1}$ because, while very low transitions rates convey reliable information since they are drawn from large initial populations, they do not allow to compute accurate measures of average accepted wages. Table A.2 summarizes the empirical and theoretical moments used for the estimation.

Table A.2: Moments and Identification

\begin{tabular}{ll}
\hline Empirical moments & Theoretical moments \\
\hline labour force in city $j \in \mathcal{J}$ & $m_{j}$ \\
Transition rate ee within city $j \in \mathcal{J}$ & $\lambda_{j}^{e} \int_{\underline{w}}^{\bar{w}} \bar{F}_{j}(x) d G_{j}(x)$ \\
Transition rate eu within city $j \in \mathcal{J}$ & $\delta_{j}$ \\
Earning distribution in city $j \in \mathcal{J}$ & $G_{j}(\cdot)$ \\
\hline Transition rate ue out of city $j \in \mathcal{J}$ & $\sum_{k \in \mathcal{J}_{j}} s_{j k}^{u} \lambda_{k}^{u} \bar{F}_{k}\left(q_{j k}(\underline{w})\right)$ \\
Transition rate ue into city $l \in \mathcal{J}$ & $\lambda_{l}^{u} \sum_{k \in \mathcal{J}_{l}} s_{k l}^{u} \bar{F}_{l}\left(q_{k l}(\underline{w})\right)$ \\
Transition rate ee out of city $j \in \mathcal{J}$ & $\sum_{k \in \mathcal{J}_{j}} s_{j k}^{e} \lambda_{k}^{e} \int_{\underline{w}}^{\bar{w}} \bar{F}_{k}\left(q_{j k}(x)\right) d G_{j}(x)$ \\
Transition rate ee into city $l \in \mathcal{J}$ & $\lambda_{l}^{e} \sum_{k \in \mathcal{J}_{l}} s_{k l}^{e} \int_{\underline{w}}^{\bar{w}} \bar{F}_{k}\left(q_{k l}(x)\right) d G_{k}(x)$ \\
Transition rate ue from city $j$ to city $l,(j, l) \in \mathcal{T}_{1}$ & $s_{j l}^{u} \lambda_{l}^{u} \bar{F}_{l}\left(q_{j l}(\underline{w})\right)$ \\
Transition rate ee from city $j$ to city $l,(j, l) \in \mathcal{T}_{1}$ & $s_{j l}^{e} \lambda_{l}^{e} \int_{\underline{w}}^{\bar{w}} \bar{F}_{l}\left(q_{j l}(x)\right) d G_{j}(x)$ \\
\hline Accepted wage ee between city $j$ and city $l,(j, l) \in \mathcal{T}_{2}$ & $q_{j l}(\cdot)$ \\
\hline
\end{tabular}

Notes: (i) Population in city $j$ : number of individuals observed in the panel between 2002 and 2007 in city $j$; (ii) Transition ee within city $j$ : ratio of the number of job-to-job transitions within city $j$ observed over the period, to the potentially-employed population in city $j$ (population as defined above multiplied by one minus the unemployment rate as defined as the ratio of the number of individuals who should be in the panel in city $j$ on $01 / 01 / 2002$ but are unobserved to the sum of this number and the number of individuals observed in city $j$ on $01 / 01 / 2002)$; (iii) Transition eu within city $j$ : ratio of the number of transitions into unemployment on the potentially-employed population; (iv) Earning distribution in city $j$ : quantiles in city $j$ on a grid of 17 wages over the period; (v) Transition ue (resp., ee) out of city $j$ : ratio of the number of transitions out of unemployment (resp., the number of job-to-job transitions) out of city $j$ observed over the period, to the potentially-unemployed (resp., potentially-employed) population in city $j$ (population as defined above multiplied by the unemployment rate as defined above); (vi) Transition ue (resp., ee) into city $l$ : ratio of the number of transitions out of unemployment (resp., the number of job-to-job transitions) into city $l$ observed over the period, to the potentially-unemployed (resp., potentially-employed) population in all cities $k \neq l$; (vii) Transition rate ue (resp., ee) from city $j$ to city $l$ : ratio of the number of transitions out of unemployment (resp., the number of job-to-job transitions) from city $j$ to city $l$ observed over the period, to the potentially-unemployed (resp., potentially-employed) population in city $j$; (viii) Accepted wages ee from city $j$ to $l$ : average wage following a job-to-job transition from city $j$ to city $l$ observed over the period. 


\section{Placebo decompositions}

Table A.3: Local unemployment rate as a function of the other group's parameters

\begin{tabular}{lcccccc}
\hline & \multicolumn{3}{c}{ Blue-collar } & \multicolumn{3}{c}{ White-collar } \\
& $(1)$ & $(2)$ & $(3)$ & $(4)$ & $(5)$ & $(6)$ \\
\hline$\delta_{j}$ & 0.109 & 0.039 & 0.092 & -0.012 & 0.123 & 0.102 \\
& $(0.166)$ & $(0.127)$ & $(0.156)$ & $(0.113)$ & $(0.144)$ & $(0.144)$ \\
$\lambda_{j}^{u}$ & & 0.171 & 0.107 & & 0.219 & 0.190 \\
& & $(0.187)$ & $(0.254)$ & & $(0.169)$ & $(0.164)$ \\
$\sum_{k \in \mathcal{J}_{j}} s_{j k}^{u} \lambda_{k}^{u}$ & & & 0.199 & & & 0.139 \\
& & & $(0.229)$ & & & $(0.105)$ \\
\hline R-squared & 0.012 & 0.036 & 0.072 & 0.000 & 0.030 & 0.049 \\
\hline
\end{tabular}

Notes: (i) OLS regressions of the estimated local unemployment rate on the structural parameters of the other group; (ii) All variables are standardized and a constant term is included; (iii) Robust standard errors in parentheses; (iv) ${ }^{* * *}$ and ${ }^{* * *}$ respectively denote significance at the $90 \%, 95 \%$ and $99 \%$ confidence levels.

Table A.4: Local average wage as a function of the other group's parameters

\begin{tabular}{lcccccc}
\hline & \multicolumn{3}{c}{ Blue-collar } & \multicolumn{3}{c}{ White-collar } \\
& $(1)$ & $(2)$ & $(3)$ & $(4)$ & $(5)$ & $(6)$ \\
\hline $\int_{\underline{w}}^{\bar{w}} x d F_{j}(x)$ & 0.144 & 0.160 & 0.132 & $0.460^{* * *}$ & $0.377^{* *}$ & $0.295^{*}$ \\
Unemployment rate & $(0.150)$ & $(0.167)$ & $(0.178)$ & $(0.153)$ & $(0.142)$ & $(0.151)$ \\
& & -0.102 & -0.0159 & & $0.238^{*}$ & 0.009 \\
Population & $(0.208)$ & $(0.256)$ & & $(0.139)$ & $(0.177)$ \\
& & $0.220^{* * *}$ & 0.245 & & $0.215^{* *}$ & $0.245^{* *}$ \\
$\lambda_{j}^{e}$ & & $(0.072)$ & $(0.201)$ & & $(0.104)$ & $(0.103)$ \\
& & & -0.123 & & & -0.224 \\
$\sum_{k \in \mathcal{J}_{j}} s_{j k}^{e} \lambda_{k}^{e}$ & & & $(0.275)$ & & & $(0.349)$ \\
& & & -0.238 & & & 0.501 \\
R-squared & \multirow{2}{*}{0.021} & 0.095 & 0.150 & 0.212 & 0.328 & 0.371 \\
\hline
\end{tabular}

Notes: (i) OLS regressions of the observed local level of earnings on the average wage offers, unemployment rate, population and on-the-job search parameters for the other group; (ii) All variables are standardized and a constant term is included; (iii) Robust standard errors in parentheses; (iv) ${ }^{* * *}$ and ${ }^{* * *}$ respectively denote significance at the $90 \%, 95 \%$ and $99 \%$ confidence levels. 